\title{
Progesterone Attenuates Corticotropin-Releasing Factor- Enhanced But Not Fear-Potentiated Startle via the Activity of Its Neuroactive Metabolite, Allopregnanolone
}

\author{
Donna J. Toufexis, Carrie Davis, Alexis Hammond, and Michael Davis \\ Department of Psychiatry and Behavioral Sciences and The Center for Behavioral Neuroscience, Emory University School of Medicine, Atlanta, Georgia \\ 30322
}

Intact female rats and ovariectomized (OVX) rats with different ovarian steroid replacement regimens were tested for changes in corticotropin-releasing factor (CRF)-enhanced startle (increased acoustic startle amplitude after intracerebroventricular infusion of $1 \mu \mathrm{g}$ of CRF). OVX rats injected with estradiol (E) followed by progesterone (P) showed a blunted CRF-enhanced startle effect compared with OVX and E-injected rats. CRF-enhanced startle also was reduced significantly in lactating females (high endogenous P levels) compared with cycling rats (low to moderate P levels), as well as in non-E-primed rats when $\mathrm{P}$ was administered acutely (4 hr before testing) or chronically ( $7 \mathrm{~d}$ P replacement). The ability of $\mathrm{P}$ to attenuate CRF-enhanced startle was probably mediated by its metabolite allopregnanolone [tetrahydroprogesterone (THP)], because THP itself had a similar effect, and chronic administration of medroxyprogesterone, which is not metabolized to THP, did not blunt CRF-enhanced startle but instead slightly increased it. These data suggest that P blunts CRF-enhanced startle through a mechanism involving its neuroactive metabolite THP, although a role for the P receptor cannot be completely ruled out. Finally, neither chronic P replacement nor acute THP affected fear-potentiated startle, suggesting that $\mathrm{P}$ metabolites have an effect on the bed nucleus of the stria terminalis and anxiety rather than on the amygdala and stimulus-specific fear.

Key words: startle; BNST; progesterone; CRH; anxiety; THP

\section{Introduction}

In addition to its well known role in the release of adrenocorticotropin hormone from the anterior pituitary, corticotropinreleasing factor (CRF) acts centrally to coordinate several aspects of emotional arousal (Dunn and Berridge, 1990), and dysregulation of CRF has been implicated in the development of certain psychiatric illnesses (Arborelius et al., 1999). Intracerebroventricular (ICV) administration of CRF increases peripheral sympathetic outflow (Grosskreutz and Brody, 1988; Stephens et al., 1988), elevates respiration (Bohmer et al., 1990), inhibits gastric acid secretion (Tashe et al., 1983), and activates several brainstem nuclei to enhance attention and vigilance (Valentino and Foote, 1987, 1988; Aston-Jones et al., 1996). ICV injection of CRF also increases the amplitude of the acoustic startle reflex (Swerdlow et al., 1986; Liang et al., 1992). This effect depends on receptors in the bed nucleus of the stria terminalis (BNST), because it is prevented by chemical lesions of the BNST or by local infusion of a CRF antagonist into the lateral BNST and is mimicked by local

Received April 13, 2004; revised Sept. 14, 2004; accepted Sept. 15, 2004

This research was supported by National Institutes of Mental Health Grants MH 47840, MH 58922, MH 52384, and MH 59906, the Woodruff Foundation, and the Science and Technology Center (the Center for Behavioral Neuroscience of the National Science Foundation under Agreement No. IBN-9876754).

Correspondence should be addressed to Donna J. Toufexis, Department of Psychiatry and Behavioral Sciences and The Center for Behavioral Neuroscience, Emory University School of Medicine, Yerkes Neuroscience Building, Room 5222, 954 Gatewood Road, Atlanta, GA 30329. E-mail: dtoufe@yahoo.com.

DOI:10.1523/JNEUROSCI.1386-04.2004

Copyright $\odot 2004$ Society for Neuroscience $\quad 0270-6474 / 04 / 2410280-08 \$ 15.00 / 0$ infusion of CRF into the same area (Lee and Davis, 1997). In contrast, the amygdala, which is critically involved in fearpotentiated startle (increased startle amplitude elicited in the presence of a cue previously paired with shock), is not involved in CRF-enhanced startle (Lee and Davis, 1997).

Gender differences in the prevalence of psychiatric disorders are well documented within the clinical literature. Women suffer from major depression and anxiety disorders at rates significantly higher than men (Sloan and Kornstein, 2003). Moreover, the occurrence of depression and anxiety-based pathologies increases significantly after puberty in women, and the incidence is highest during a woman's reproductive years, suggesting that ovarian hormones are involved in the etiology of these pathologies (Palanza, 2001; Born et al., 2002). Studies in rodents also indicate gender differences in emotional behavior. Female rats often exhibit less fear or anxiety-like behavior than do their male conspecifics (Steenbergen et al., 1990; Johnson and File, 1991; Fernandes et al., 1999), especially during the period of proestrous, when the ovarian hormones estrogen (E) and progesterone $(\mathrm{P})$ are at their zenith. Proestrous females show reduced periods of immobility in the Porsolt forced swim tests, increased latencies in burying an electrified prod, and more time spent in the open arms of the elevated plus maze than diestrous females (Frye et al., 2000; Marcondes et al., 2001; Frye and Wawrzychi, 2003). Hence, ovarian steroids affect emotionality in female rats as they do in women.

To date, CRF-enhanced startle has been studied only in male 
rats, and only a handful of studies have looked at sex differences in fear conditioning (Anagnostaras et al., 1998; Pryce et al., 1999; Gupta et al., 2001; Stock et al., 2001). Moreover, the influence of steroid hormones on anxiogenic effects produced by ICV CRF versus those produced by fear conditioning has yet to be determined. In this study, we begin the examination of ovarian hormone effects on CRF-enhanced and fear-potentiated startle in the female rat.

\section{Materials and Methods General methods}

Animals. Female Sprague Dawley rats (Charles River, Raleigh, NC), weighing between 250 and 300 gm were maintained on a $12 \mathrm{hr}$ light/dark cycle (lights on at 8:00 A.M.) with food and water available ad libitum. Rats were initially group-housed in $45 \times 24 \times 20 \mathrm{~cm}$ polycarbonate cages (four rats per cage) and individually housed after implantation of ICV cannulas. In all experiments, intact or ovariectomized (OVX) rats obtained from the supplier were maintained in the vivarium for 2 weeks before startle testing.

Apparatus. Rats were trained and tested in two identical $8 \times 15 \times 15$ $\mathrm{cm}$ Plexiglas and wire mesh cages. The floor of each cage consisted of four 6.0 -mm-diameter stainless steel bars spaced $18 \mathrm{~mm}$ apart. The cages were suspended between compression springs within a steel frame, and both were enclosed in a ventilated, sound-attenuating chamber (inside dimensions, $56 \times 56 \times 81 \mathrm{~cm}$; Industrial Acoustics, Bronx, NY). Background noise (60 dB; wideband) was provided by a General Radio (Concord, MA) type 1390-B noise generator and delivered through high-frequency speakers (Supertweeter; Radio Shack, Tandy, Fort Worth, TX) located $5 \mathrm{~cm}$ from the front of each cage. Sound level measurements were made with a Brüel \& Kjaer (Marlborough, MA) model 2235 sound-level meter (A scale; random input) with the microphone (type 4176) located $7 \mathrm{~cm}$ from the center of the speaker, which approximates the distance of the rat's ear from the speaker during testing.

Startle responses were evoked by $50 \mathrm{msec}$ white-noise bursts $(5 \mathrm{msec}$ rise-decay) generated by a Macintosh G3 computer sound file (0-22 $\mathrm{kHz}$ ), amplified by a Radio Shack amplifier (100 watt; model MPA-200), and delivered through the same speakers as those used to provide background noise. Startle response amplitudes were quantified using an Endevco (San Juan Capistrano, CA) 2217E accelerometer . Cage movement produced by the rat's startle response resulted in displacement of the accelerometer, the output of which was integrated, producing a voltage output proportional to the velocity of cage movement. This signal was amplified by an Endevco model 104 amplifier and digitized on a scale of $0-2500$ units by an InstruNET device (model 100B; GW Instruments, Somerville, MA) interfaced to a Macintosh G3 computer. Startle amplitude was defined as the maximal peak-to-peak voltage that occurred during the first $300 \mathrm{msec}$ after onset of the startle-eliciting noise burst.

In the fear-potentiated startle test, the visual conditioned stimulus was a $3.7 \mathrm{sec}$ light (200 lux) produced by a $25 \mathrm{~W}$ incandescent bulb located 25 $\mathrm{cm}$ above each cage. Luminosity was measured using a VWR (Atlanta, GA) light meter. The unconditioned stimulus was a $0.5 \mathrm{sec}, 0.4 \mathrm{~mA}$ shock delivered through the four floor bars. Shock intensity was measured with a $1 \mathrm{k} \Omega$ resistor across a differential channel of an oscilloscope in series with a $100 \mathrm{k} \Omega$ resistor connected between adjacent floor bars within each cage. Current was defined as the root-mean-square voltage across the 1 $\mathrm{k} \Omega$ resistor where milliamperes $=0.707 \times 0.5 \times$ peak-to-peak voltage. Shocks were produced by LeHigh Valley shock generators (SGS-004; Beltsville, MD). The presentation and sequencing of all stimuli were under the control of the Macintosh G3 computer using custom-designed software (The Experimenter; Glassbeads Inc., Newton, CT).

Surgery. Rats were anesthetized with a ketamine-xylazine mixture (ketamine, $100 \mathrm{mg} / 100 \mathrm{ml}$; xylazine, $20 \mathrm{mg} / \mathrm{ml}$ at $1 \mathrm{cc} / \mathrm{kg}$, i.p.) and placed in a stereotaxic instrument (ASI, Warren, MI). The skull was exposed, a hole was drilled over the lateral ventricle, and a 22 gauge guide cannula (model C313G; Plastic Products, Roanoke, VA) was lowered into the right lateral ventricle (anteroposterior, -0.4 ; dorsoventral, -5.5 ; mediolateral, $+1.2 \mathrm{~mm}$ from bregma; nosebar set to $+5.0 \mathrm{~mm}$ ). Four jeweler's screws were anchored to the skull, and the assembly was cemented in place using Cranioplastic Powder (Plastic Products). A dummy cannula (model C313DC/l; Plastic Products) was inserted into the guide cannula to maintain patency before returning the rats to the vivarium. One week later, the accuracy of cannula placement was determined using the angiotensin II drinking test in which $50 \mathrm{ng}$ of angiotensin II was infused and the latency to drink recorded. Animals that did not initiate drinking within 2 min were eliminated from the experiment.

Matching procedure. Rats were presented with 3095 dB, 50 msec bursts of white noise (startle stimuli) at a $30 \mathrm{sec}$ interstimulus interval (ISI). The rats were then divided into groups that had equivalent mean startle amplitudes across the 30 startle stimuli.

CRF-enhanced startle. On the test day, rats were given $60105 \mathrm{~dB}$ startle stimuli at a $30 \mathrm{sec}$ ISI (baseline startle test) and then removed for $1 \mathrm{hr}$. After this period, all rats were infused with $1 \mu \mathrm{g}$ of CRF (human-rat CRF; Sigma, St. Louis, MO) in $5 \mu$ l of artificial CSF over $2 \mathrm{~min}$, a dose previously demonstrated to produce a robust increase in startle. Infusion cannula were left in the ventricle for an additional $2 \mathrm{~min}$. The rats were then returned to the startle chambers and presented with $240105 \mathrm{~dB}$ startle stimuli at a $30 \mathrm{sec}$ ISI.

Radioimmunoassays. Plasma progesterone and leutinizing hormone (LH) levels were measured using standard radioimmunoassays described in the literature (Trawick and Bahr, 1986; Kornblatt and Grattan 2001) by the Yerkes Neuroendocrine Laboratory.

Fear-potentiated startle training. Two days after matching, rats were placed in the startle test cages and 5 min later given 10 light-shock pairings consisting of a $3.7 \mathrm{sec}, 200$ lux light coterminating with a $0.5 \mathrm{sec}, 0.4$ $\mathrm{mA}$ footshock at an average intertrial interval of $3 \mathrm{~min}$ (range, 2-4 min). This procedure was repeated the following day.

Fear-potentiated startle testing. Eight days later, all animals were returned to the training chambers and presented with $3095 \mathrm{~dB}$ startle stimuli (Noise-Alone trials) at a $30 \mathrm{sec}$ ISI followed $30 \mathrm{sec}$ later by the first of 30 light plus startle stimulus trials (Light-Noise trials) and 30 NoiseAlone trials in a balanced, irregular order. On the Light-Noise trials, the startle stimulus occurred $3.2 \mathrm{sec}$ after onset of the light.

Data analysis. CRF-enhanced startle data were analyzed using percentage increase from baseline, because this method has proven to be more accurate than scoring absolute values in determining levels of fear and anxiety (Walker and Davis, 2002). CRF-enhanced startle data were first collapsed over 10 min blocks of 20 startle stimuli. The mean startle amplitude before drug infusion was computed for each rat and used as the baseline startle amplitude for that animal. The data during the 12 blocks after drug infusion for each animal were computed as a percentage change in startle relative to this baseline. These percentage changes scores were then analyzed with two-way ANOVA with treatment (e.g., P vs Vehicle) as a between-subjects factor and trial block (i.e., 10-120 min) as a within-subjects factor. Fear-potentiated startle was analyzed with ANOVA with repeated measures using both absolute and percentage values.

\section{Specific methods}

Experiment 1: CRF-enhanced startle in OVX females with estrogen alone or estrogen plus progesterone replacement regimens. The purpose of this experiment was to evaluate the effect of $\mathrm{E}$ and $\mathrm{P}$ on CRF-enhanced startle. OVX rats were used to reduce lingering levels of these steroids or their metabolites. Rats were implanted with ICV cannulas, as described above. After a $10 \mathrm{~d}$ recovery period, they were matched, as described above, into three initial groups of eight rats each that had equivalent mean startle amplitudes. Because of loss of cannula or failure to respond in the angiotensin II drinking test, six rats were removed from this study. Groups consisted of: OVX (oil injected; $n=5$ ); OVX plus E replacement (1 $\mu \mathrm{g} / 100 \mu$ l, s.c. estradiol in corn oil injected $24 \mathrm{hr}$ before; $250 \mu \mathrm{g} / 100 \mu \mathrm{l}$, s.c. estradiol in corn oil injected $4 \mathrm{hr}$ before testing; $n=6$; this dose has been used to induce LH in OVX and lactating rats) (Todd et al., 2003; Abizaid et al., 2004); or OVX plus E plus P ( $1 \mu \mathrm{g} / 100 \mu \mathrm{l}$, s.c. estradiol in corn oil injected $24 \mathrm{hr}$ before; $250 \mu \mathrm{g} / 100 \mu \mathrm{l}$, s.c. estradiol in corn oil injected followed $20 \mathrm{hr}$ later by $500 \mu \mathrm{g} / 100 \mu \mathrm{l}$, s.c. P in corn oil; $n=7$; with testing taking place $4 \mathrm{hr}$ after $\mathrm{P}$ injection). These doses have been used to induce LH in OVX and lactating rats (Todd et al., 2003; Abizaid 
et al., 2004). On the test day, the rats were tested before and after ICV infusion of CRF, as described above.

Experiment 2: CRF-enhanced startle in OVX females with acute $P$ replacement. The purpose of this study was to examine the effect of acute $\mathrm{P}$, without estrogen priming, on CRF-enhanced startle in female rats. OVX rats were implanted with ICV cannulas and $10 \mathrm{~d}$ later matched and divided into two groups of 10 rats each. One group was given a single injection of $\mathrm{P}(500 \mu \mathrm{g} / 100 \mu \mathrm{l})$. The other group was given a single injection of the vehicle, corn oil $(100 \mu \mathrm{l})$. Four hours after injection, rats were tested for CRF-enhanced startle, as described above.

Experiment 3: CRF-enhanced startle in OVX females with chronic $P$ replacement. The purpose of this study was to examine the effect of chronic $\mathrm{P}$, without estrogen priming, on CRF-enhanced startle. OVX rats were implanted with ICV cannulas and $10 \mathrm{~d}$ later matched and divided into two groups of eight rats each. One rat was subsequently removed after failing the angiotensin II drinking test. The chronic P group was implanted subcutaneously in the back of the neck under light halothane anesthesia [with SILASTIC (Dow Corning, Midland, MI) capsules filled with P; length, $6 \mathrm{~cm}$; 0.078 inch inner diameter (I.D.); 0.125 inch outer diameter (O.D.); $n=8$ ]. Controls (blanks; $n=7$ ) were implanted with empty capsules. CRF-enhanced startle was measured on day 8 after $7 \mathrm{~d}$ of capsule implantation. After testing, tail blood was sampled from eight chronic $\mathrm{P}$ and blank rats and assayed for plasma $\mathrm{P}$ concentrations.

Experiment 4: CRF-enhanced startle in intact females with different endogenous $P$ levels. The purpose of this experiment was to examine the effect of endogenous $P$ levels in intact female rats known to differ with respect to plasma P level. Intact Sprague Dawley females were matched and divided into two groups of eight rats each. One group was allowed to mate and subsequently separated into individual cages $\sim 2 \mathrm{~d}$ before birth. Intact virgin females were housed individually for approximately the same duration before surgery and testing as postpartum females. Intact virgin and lactating rats (on postpartum day 2 ) underwent cannula implantation, as described previously. Three rats, two virgin and one lactating, were removed from the study because of loss of cannula. After a $12 \mathrm{~d}$ recovery period (postpartum day 14 for lactating females), they were tested for CRF-enhanced startle (intact, $n=6$; lactating, $n=7$ ).

Experiment 5: effect of allopregnanolone on baseline and CRF-enhanced startle in OVX rats. The purpose of this experiment was to assess the effect of allopregnanolone [tetrahydroprogesterone (THP)], the major metabolite of P, on CRF-enhanced startle. OVX Sprague Dawley females $(n=$ 8) underwent cannula implantation, and $10 \mathrm{~d}$ later they were matched. Rats were each tested twice for CRF-enhanced startle. On the first test day, half the rats were injected with THP (10 mg/kg, i.p. dissolved in $45 \%$ 2-hydroxypropyl- $\beta$-cyclodextrin) and tested $4 \mathrm{hr}$ later for CRFenhanced startle. The other half was tested after infusion of the vehicle alone. At least $2 \mathrm{~d}$ later, these procedures were repeated except that rats given THP on day 1 were now given only the vehicle and vice versa. The same procedure was used on another group of OVX rats $(n=8)$ without CRF infusion to measure baseline startle in THP-treated females.

Experiment 6: CRF-enhanced startle in OVX rats replaced with $P$ or medroxy-progesterone. Because the experiments above suggested that the effect of $\mathrm{P}$ on CRF-enhanced startle was probably attributable to its conversion to THP, experiment 6 evaluated how medroxy-progesterone (MPA), which binds to the P receptor but is not metabolized to THP, would affect CRF-enhanced startle. OVX rats underwent cannula implantation and were matched and divided into two groups of eight rats each. One group was implanted with SILASTIC capsules (length, $6 \mathrm{~cm}$; 0.078 inch I.D.; 0.125 inch O.D.) filled with P, and the other group received capsules filled with MPA (length, $12 \mathrm{~cm}$; 0.078 inch I.D.; 0.125 inch O.D.; Sigma). Three rats, one replaced with $\mathrm{P}$ and two replaced with MPA, were removed from the study because of missing or clogged cannulas. Eight days later, they were tested for CRF-enhanced startle. As a positive control for the action of P and MPA, plasma LH levels were measured in all MPA- and P-replaced females and compared with those of OVX nonreplaced rats from the previous experiments. Because of lack of ovarian steroid negative feedback, OVX rats should have higher levels of plasma LH compared with P- and MPA-replaced OVX females (Rabii and Ganong, 1976)

Experiment 7: effect of chronic P on fear-potentiated startle in OVX rats.

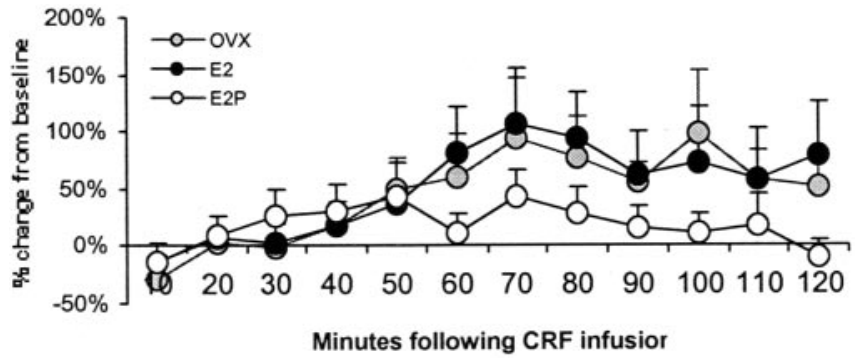

Figure 1. Percentage change from baseline startle ( \pm SEM) in OVX (gray circles; $n=5$ ), OVX estrogen-replaced (E2; black circles; $n=6$ ), and OVX estrogen-primed, P-replaced (E2P; white circles; $n=7$ ) female rats after ICV CRF infusion. Data were collapsed into 10 min intervals of 20 startle stimuli.

The purpose of this experiment was to determine whether chronic progesterone would affect the expression of fear-potentiated startle. OVX female rats were matched into two groups of 10 rats each and trained for the fear-potentiated startle, as described above. One day after training, the chronic P group was implanted subcutaneously with SILASTIC capsules (0.078 inch, I.D.; 0.125 inch, O.D.) filled with P. Controls (blanks) were implanted with empty capsules. One animal, which appeared very sick, was removed from the blank group before testing. Seven days later, all rats were tested for fear-potentiated startle, as described previously.

Experiment 8: effect of acute THP on fear-potentiated startle in OVX rats. The purpose of this experiment was to determine whether acute THP would affect the expression of fear-potentiated startle. OVX female rats $(n=8)$ were trained for the fear-potentiated startle as described above. Two days after training, four of the rats were injected with THP (10 $\mathrm{mg} / \mathrm{kg}$ ) and four were injected with vehicle. Four hours later, all rats were tested for fear-potentiated startle, as described previously. All rats were then retrained and $2 \mathrm{~d}$ later tested again, except that rats given THP on day 1 were now given only the vehicle and vice versa.

\section{Results}

Experiment 1: CRF-enhanced startle in OVX females with estrogen alone or estrogen plus progesterone replacement regimens

In this and all subsequent studies, there were no significant group effects or group by time interactions during the preinfusion baseline test. As shown in Figure 1, all groups showed a significant increase in acoustic startle amplitude across the $2 \mathrm{hr}$ test session (CRF-enhanced startle; $\left.F_{(11,165)}=5.50 ; p<0.0001\right)$. The overall time by group interaction was not significant. Subsequent comparisons indicated that the OVX alone and OVX plus E groups did not differ across time, but when these groups were compared with the OVX E plus $\mathrm{P}$ groups, there was a significant group by time interaction $\left(F_{(11,176)}=2.48 ; p<0.007\right)$.

\section{Experiment 2: CRF-enhanced startle in OVX females with acute $P$ replacement}

Figure $2 A$ shows that both the OVX and OVX plus $\mathrm{P}$ rats showed significant CRF-enhanced startle $\left(F_{(11,198)}=5.776 ; p<0.0001\right)$. However, the magnitude of this was lower in the group given acute $\mathrm{P}$, and this was supported by a significant overall group effect $\left(F_{(1,18)}=5.662 ; p<0.03\right)$ as well as a significant group by time interaction effect $\left(F_{(11,198)}=1.83 ; p<0.05\right)$

\section{Experiment 3: CRF-enhanced startle in OVX females with chronic $P$ replacement}

Figure $2 B$ shows that chronic $\mathrm{P}$ also blunted $\mathrm{CRH}$ enhanced startle. Thus, there was a significant overall effect of CRF $\left(F_{(11,143)}=\right.$ 9.99; $p<0.0001)$ as well as a significant group by time interaction $\left(F_{(11,143)}=2.40 ; p<0.009\right)$, reflecting the smaller increase in the 


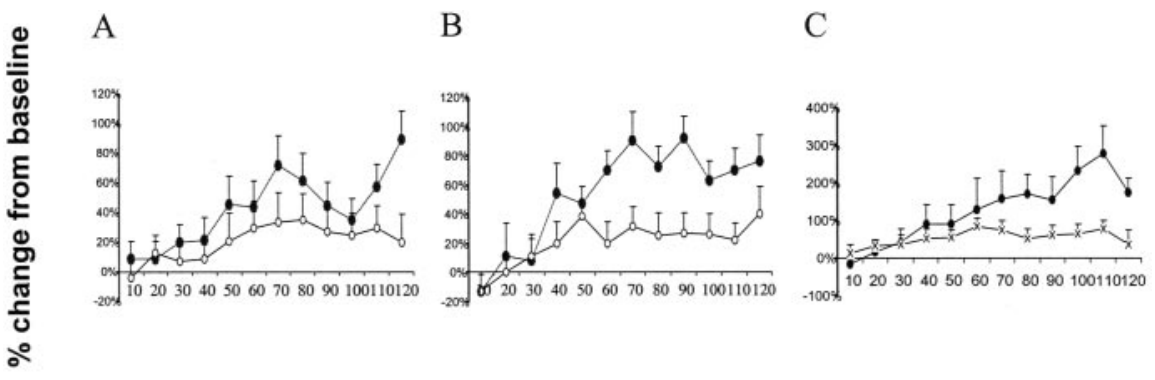

Minutes following CRF infusion

Figure 2. Percentage change from baseline startle ( \pm SEM) after ICV CRF infusion in: $A, 0 V X$ rats injected with oil alone (dark circles; $n=10)$ or progesterone (white circles; $n=10)(500 \mu \mathrm{g} / 100 \mu$ loil) $4 \mathrm{hr}$ before the CRF test; $B, 0 \mathrm{VX}$ rats implanted for $7 \mathrm{~d}$ with blank SILASTIC capsules (dark circles; $n=7$ ) or P-filled capsules (white circles; $n=8$ ); and C, intact virgin (dark circles; $n=$ 6) and lactating ( $\left.X_{S} ; n=7\right)$ female rats. Data from all three studies were collapsed into 10 min intervals of 20 startle stimuli.

lactating females as reflected by a significant group by time interaction $\left(F_{(11,121)}=6.42 ; p<0.001\right)$.

Experiment 5: effect of THP on baseline and CRF-enhanced startle in OVX rats

Figure $3 A$ shows that THP reduced CRFenhanced startle. Thus, there was a significant overall effect of CRF $\left(F_{(11,154)}=\right.$ 7.534; $p<0.001)$ as well as a significant group effect $\left(F_{(1,14)}=8.925 ; p<0.01\right)$. As shown in Figure $3 B$, THP did not significantly affect baseline startle (ANOVA: group, $F_{(1,14)}=0.619, p>0.44$; group by time, $\left.F_{(11,152)}=0.672, p>0.76\right)$.

\section{Experiment 6: CRF-enhanced startle in}
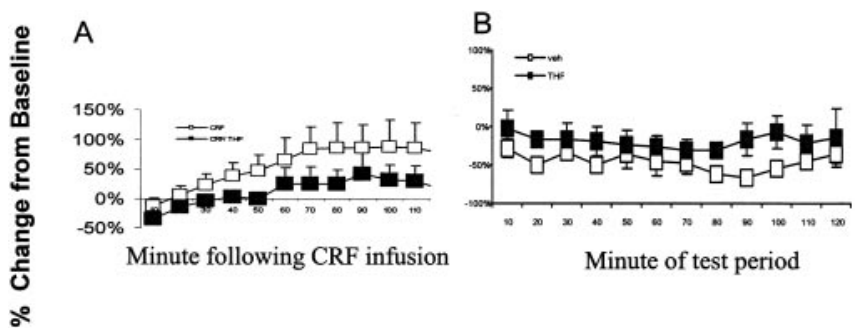

Figure 3. Percentage change from baseline startle ( \pm SEM) in: $A$, OVX rats $(n=8)$ tested for CRF-enhanced startle with (dark squares) and without (white squares) intraperitoneal injection of THP ( $10 \mathrm{mg} / \mathrm{kg}$, by weight); and $B$, changes in baseline startle over a $2 \mathrm{hr}$ period in OVX rats $(n=8)$ after injection of THP (dark squares) or vehicle (veh; white squares).

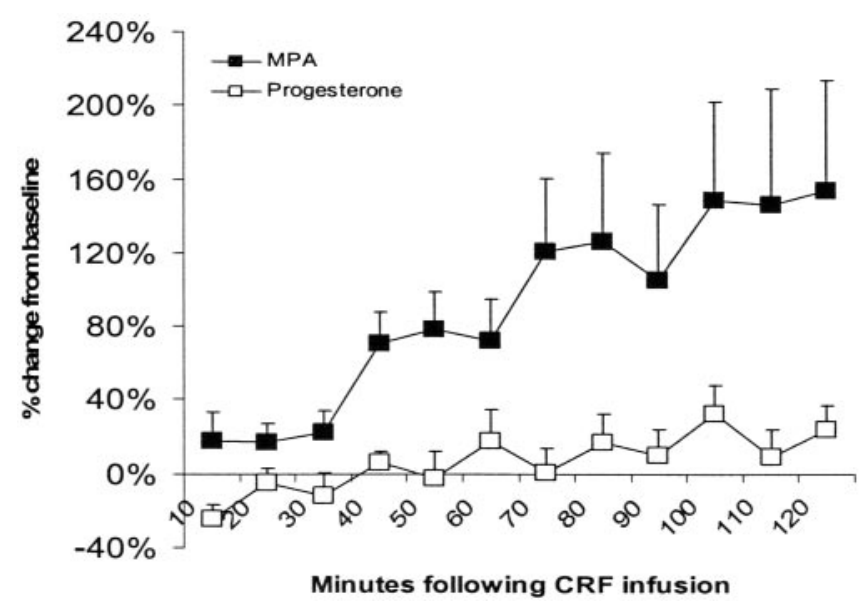

Figure 4. Percentage change from baseline startle ( \pm SEM) after ICV CRF infusion in OVX rats implanted with MPA (dark squares; $n=6$ ) or $P$ ( white squares; $n=7$ ). Data were collapsed into 10 min intervals of 20 startle stimuli.

chronic P rats. Radioimmunoassay on plasma sampled from progesterone-treated rats showed high levels of plasma progesterone $(21.3+/-3.1 \mathrm{ng} / \mathrm{ml})$. Blank-replaced rats had negligible plasma progesterone.

\section{Experiment 4: CRF-enhanced startle in virgin versus lactating rats}

Figure $2 C$ shows that both intact virgin and lactating rats showed a significant increase in startle amplitude after CRF infusion $\left(F_{(11,121)}=8.37 ; p<0.001\right)$. Intact virgin females showed significantly greater CRF-enhanced startle over time compared with

\section{OVX rats replaced with $P$ or MPA}

Figure 4 shows the typically blunted CRF effect in the P-treated rats in contrast to a high level of CRF-enhanced startle in the MPA-treated rats. This was reflected by a significant group effect $\left(F_{(1,11)}=8.77 ; p<0.016\right)$ as well as a significant group by time interaction $\left(F_{(11,121)}=2.43 ; p<0.009\right)$. Inspection of Figure 4 suggested that the magnitude of CRF-enhanced startle was unusually high in the MPA-treated group. To test this statistically, the results for all of the OVX control rats in the previous experiments were combined and compared with the data of the MPA rats (Fig. 5). Based on this comparison, the MPA rats did show greater CRF-enhanced startle as reflected by a significant group by time interaction $\left(F_{(11,286)}=1.976 ; p<0.031\right)$. Although additional comparisons within the same cohort of rats need to be made, these results suggest that MPA may actually have increased CRF-enhanced startle, in contrast to the consistent blunting produced by $\mathrm{P}$.

Table 1 shows the serum LH levels of OVX rats and OVX rats replaced with MPA and P. A one-way ANOVA found a significant difference among the groups $\left(F_{(2,17)}=9.22 ; p<0.002\right)$. Post hoc contrasts using Tukey's correction for multiple comparisons found a significant difference between the OVX group and the P-replaced group $(p<0.02)$ and the MPA-replaced group $(p<$ 0.002 ). Results indicate that both $P$ and MPA were sufficient to decrease plasma LH levels, as has been reported previously in women and male rats (Bagis et al., 2002; Jai et al., 2002; Saaresranta et al., 2002).

\section{Experiment 7: effect of chronic $\mathrm{P}$ on fear-potentiated startle in OVX rats}

Figure $6 \mathrm{~A}$ shows the magnitude of fear-potentiated startle in OVX rats and OVX rats with chronic $P$ replacement. In contrast to its effects on $\mathrm{CRH}$-enhanced startle, chronic $\mathrm{P}$ did not reduce either baseline or fear-potentiated startle. Thus, there was a significant effect of trial type (i.e., higher startle amplitude in the presence vs the absence of the cue; fear-potentiated startle) $\left(F_{(1)}=\right.$ 58.869; $p<0.001)$, but there was no significant effect of group $\left(F_{(1,17)}=0.075 ; p=0.788\right)$ or group by trial-type interaction $\left(F_{(1,17)}=0.011 ; p=0.878\right)$.

\section{Experiment 8: effect of acute THP on fear-potentiated startle in OVX rats}

Figure $6 B$ shows the magnitude of fear-potentiated startle in OVX rats and OVX rats injected with THP $4 \mathrm{hr}$ before testing. Again, in contrast to its effects on CRH-enhanced startle, there was no effect of THP on either baseline or fear-potentiated startle. 


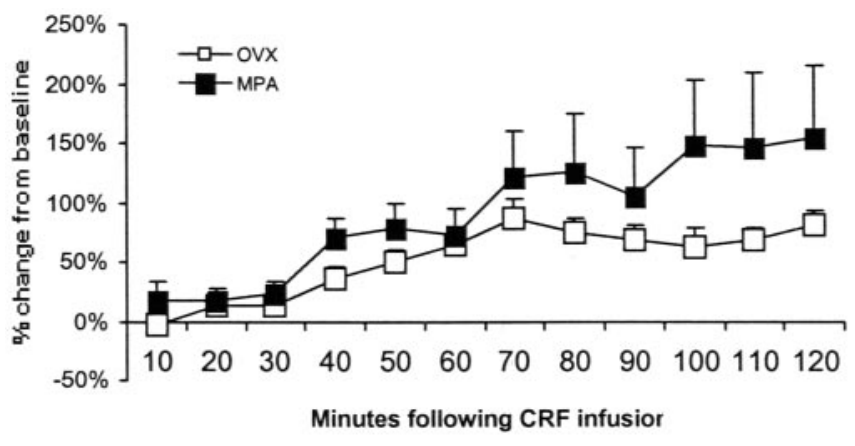

Figure 5. Percentage change from baseline startle ( \pm SEM) after ICV CRF infusion in OVX rats (white squares; $n=22$ ) and those implanted with SILASTIC capsules filled with MPA (dark squares; $n=6$ ). Data were collapsed into 10 min intervals of 20 startle stimuli.

Table 1. Serum luteinizing hormone levels in rats replaced with SILASTIC tubing containing progesterone $(n=7)$, medroxy-progesterone $(n=5)$, and untreated $(n=8)$

\begin{tabular}{ll}
\hline Groups & LH (in nanograms per milliliter) \\
\hline Untreated & $6.62 \pm 0.96^{*}$ \\
MPA-filled & $1.42 \pm 0.51$ \\
P-filled & $3.15 \pm 0.9$ \\
\hline
\end{tabular}

*Significantly higher than MPA- and P-implanted animals.

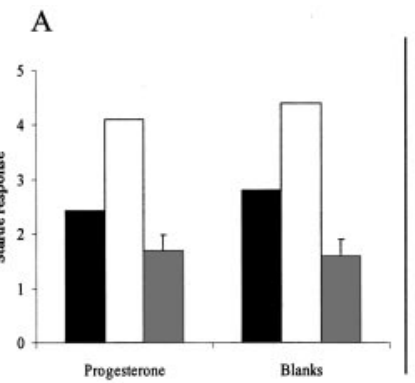
B

Figure 6. Fear-potentiated startle in: $A, 0 \mathrm{VX}$ rats implanted for $7 \mathrm{~d}$ with blank capsules $(n=$ 8) or P-filled capsules $(n=9)$ and $B, O V X$ rats $(n=8)$ tested $4 \mathrm{hr}$ after either THP (10 $\mu \mathrm{g} / \mathrm{kg}$, by weight) injection or vehicle. Graph shows startle amplitude in the presence (light noise; white bars) and absence (noise alone; black bars) of the light cue. The difference between the two trial types (light-noise - noise alone $=$ fear-potentiated startle; \pm SEM) is depicted by gray bars.

Thus, there was a significant effect of trial type (i.e., fearpotentiated startle $)\left(F_{(1)}=26.538 ; p<0.001\right)$ but no significant effect of group $\left(F_{(1,14)}=0.074 ; p=0.70\right)$ or group by trial-type interaction $\left(F_{(1,14)}=0.066 ; p=0.72\right)$

\section{Discussion}

This study showed that gonadal steroids modulate the effects of ICV CRF on the acoustic startle reflex in female rats. In OVX rats, replacement of $\mathrm{P}$ in estrogen-primed females or acutely, as well as chronically, in non-estrogen-primed females, significantly attenuated CRF-enhanced startle, whereas baseline startle remained unchanged. A similar effect was seen in lactating females, in which plasma $\mathrm{P}$ is chronically elevated and estrogen levels are low. In contrast, chronic P did not affect the expression of fearpotentiated startle, suggesting that $\mathrm{P}$ affects brain regions, such as the BNST, essential for CRF-enhanced startle and not systems involving the central nucleus of the amygdala, critical for the expression of fear-potentiated startle (Walker and Davis, 1997).

The ability of $\mathrm{P}$ to decrease CRH-enhanced startle could have resulted from activation of its receptor(s), through activity of its metabolites, or a combination of these factors. $\mathrm{P}$ is rapidly con- verted to $3 \alpha, 5 \alpha$-pregnan-20-one (allopregnanolone-THP) (Stoffel-Wagner et al., 2003) that does not bind to the P receptor but exerts strong positive allosteric modulation of the $\mathrm{GABA}_{\mathrm{A}}$ receptor (Gulinello and Smith, 2003).

Several lines of evidence implicate THP in the reduction of CRF-enhanced startle induced by P. THP has been shown to play a role both in the response to, and in the effect of, stress. For example, 5 min after swim stress, THP levels in adrenalectomized male rats are increased 4 - to 20 -fold over baseline values (Purdy et al., 1991), and serum THP is increased after injection of CRF and adrenocorticotropin hormone (Torres et al., 2001) after $\mathrm{CO}_{2}$ exposure (Barbaccia et al., 1996) and after footshock (Barbaccia et al., 1997) in male rats. The effects of THP on stress may specifically involve CRF systems. Patchev et al. (1994) demonstrated that doses of 5 and $10 \mu \mathrm{g}$ of THP ICV offset the anxiogenic effect of $0.5 \mu \mathrm{g}$ of CRF on plus maze activity in male rats and showed that stimulation of CRF release by the $\alpha-1$ receptor agonist methoxamine was inhibited in vitro by pretreatment with low molar concentrations of THP. THP also reduced stress-induced transcription of vasopressin in the ventromedial paraventricular nucleus of adrenalectomized, castrated rats (Patchev et al., 1996). Thus, the connection between THP and the stress axis, and in particular with CRF neurotransmission, might extend to interactions between THP and CRF systems in other brain regions. Indeed, a study by Swerdlow and Britton (1994) showed that alphaxalone, a synthetic pregnane steroid anesthetic, inhibits the startle-enhancing effects of CRF without affecting baseline startle or interfering with strychnine-induced facilitation of the startle response. And, in the present study, administration of THP itself also decreased CRF-enhanced startle.

THP has been shown to have profound anxiolytic properties linked to its allosteric modulation of the $\mathrm{GABA}_{\mathrm{A}}$ receptor. THP reduces anxiety in rodents in the elevated plus maze (Bitran et al., 1991; Wieland et al., 1991; Rhodes and Frye, 2001), the GellerSeifter punished response test (Carboni et al., 1996; Brot et al.,1997), the mirrored chamber test (Reddy and Kulkarni, 1997), and the defensive burying test (Fernandez-Guasti and Picazo, 1995). THP also decreases ultrasonic vocalizations in rat pups separated from their mothers (Zimmerberg et al., 1994; Vivian et al., 1997). Thus, the GABAergic activity of THP may make the major contribution to the attenuation of CRF-enhanced startle observed here. In further support of this, CRH-enhanced startle was not reduced by MPA, which binds to the $\mathrm{P}$ receptor with an equal or greater affinity to that of natural P (Jeppsson, 1981; Pridjian et al., 1987; Selman et al., 1996) but does not undergo metabolic conversion to THP (McAuley et al., 1993; Lobo, 1999).

Both acute as well as chronic $\mathrm{P}$ replacement without estrogen priming also reduced CRF-enhanced startle in OVX rats. Because most brain areas require estrogen receptor activation for induction of P receptor synthesis (Bogic et al., 1988; Simerly et al., 1996; Shughrue et al., 1997; Camacho-Arroyo et al., 1998; Allan et al., 2001), blunted CRF-enhanced startle after acute P injection without estrogen priming suggests this probably was not mediated through the $\mathrm{P}$ receptor. This is corroborated by results from the chronic $\mathrm{P}$ replacement study. $\mathrm{P}$ has been shown to downregulate its own receptor in vitro (Turgeon and Waring, 2000), a process involving the inhibition of gene transcription. Thus, when rats were tested (on day 8 of $\mathrm{P}$ replacement), the downregulation of the $\mathrm{P}$ receptor would make it unlikely that the $\mathrm{P}$ receptor activation played a major role in suppressing CRF-enhanced startle. However, Camacho-Arroyo et al. (1998) showed that P-induced $\mathrm{P}$ receptor downregulation does not occur in the hippocampus, suggesting that forebrain regions may be exempt from this effect. 
Moreover, in the present study, activation of at least some hypothalamic $\mathrm{P}$ receptors did, in fact, take place in steroid-replaced females, as witnessed by the decrease in plasma LH in both MPAand P-replaced females relative to OVX nonreplaced females (Table 1). These results indicate that the failure of MPA to block CRF-enhanced startle cannot be attributed to a complete absence of MPA-induced hypothalamic $\mathrm{P}$ receptor activation, but rather to the fact that MPA, unlike natural progestins, is not metabolized to THP.

Collectively, data presented above support the idea that the neuroactive metabolite of $\mathrm{P}, \mathrm{THP}$, is most likely responsible for inhibiting CRF-enhanced startle. However, the participation of the $\mathrm{P}$ receptor cannot be completely ruled out. Both $\mathrm{P}$ and MPA are agonists at the glucocorticoid receptor (GR), with MPA possessing a much higher affinity for GR than P (Kontula et al., 1983; Patel et al., 2003). Chronic (5 d) subcutaneous injections of corticosterone produced CRF-enhanced startle to a dose of CRF previously shown not to increase startle (Lee et al., 1994). Conceivably, this GR effect (augmentation of CRF-enhanced startle) of MPA offset any MPA-induced $P$ receptor effect (attenuation of CRF-enhanced startle). However, P and MPA may not affect GR in the same manner as glucocorticoids do. Indeed, activation of GR via progestins versus glucocorticoids results in differential gene transcription (Wan and Nordeen, 2003).

MPA, the progestin used in most hormone replacement regimens in North America, actually amplified CRF-enhanced startle over that observed in OVX controls. Interestingly, MPA has also been shown to have effects opposite to those of $\mathrm{P}$ both at the cellular level (Nilsen and Brinton, 2003) and in behavioral paradigms (Gibbs and Gabor, 2003).

CRF-enhanced startle also was attenuated in lactating females. Lactation in the rat produces a hyporesponsiveness of the stress axis (Deschamps et al., 2003), the onset of maternal behavior (Pedersen and Boccia, 2002), and a diminution of emotional responses in tests of fear and anxiety (Neumann, 2003). Although elevated $\mathrm{P}$ is only one of several hormonal changes that occur during lactation, it is interesting that a physiological state that naturally produces a sustained elevation of plasma $\mathrm{P}$ also attenuated the effects of CRF on startle. Indeed, changes in hypothalamic and limbic levels of CRF are a hallmark of lactation in the rat (Costa et al., 2001), as is the reduced responsiveness of CRF target tissues such as the pituitary (Toufexis et al., 1999b). Thus, extended exposure to $\mathrm{P}$ during lactation could be related to these changes in central CRF neurotransmission during this period.

In contrast to CRF-enhanced startle, neither chronic $\mathrm{P}$ nor acute THP attenuated expression of fear-potentiated startle. Considerable data indicate the central nucleus of the amygdala (CeA) is necessary for short-duration responses to aversive stimuli (i.e., fear-potentiated startle) (Davis, 1992), whereas the BNST mediates long-duration responses to aversive stimuli, such as the elevation in startle several minutes after rats are placed in a brightly lit startle chamber (light-enhanced startle) (Walker and Davis, 1997). The BNST, and not the CeA, is also required for the elevation of startle after central CRF infusion (Lee and Davis, 1997), and fear-potentiated and CRF-enhanced startle show additivity, consistent with the idea they work through parallel independent systems (Walker and Davis, 2002). The differential effects of P and THP on CRF-enhanced versus fear-potentiated startle suggests that progesterone may affect the BNST or related brain areas and not the CeA. This is supported by the fact that lactating rats show blunted CRF-enhanced startle (current study) but no reduction in fear-potentiated startle (Toufexis et al., 1999a). Because the BNST is implicated in emotional reactivity more akin to anxiety than stimulus-specific fear (Walker et al., 2003), the current results suggest that $P$ may be affecting brain systems involved in anxiety versus stimulus-specific fear. In agreement with this, a recent study reported that neither THP nor $\mathrm{P}$ reduced the suppression of motility after the onset of conditioned fear stimulus (Noda et al., 2000).

Dysregulation of CRF is seen in several psychiatric disorders (Gutman and Nemeroff, 2002). Moreover, CRF is increased, and THP is reduced, in the cerebrospinal fluid of depressed patients, and these concentrations normalize after treatment with antidepressant drugs (Nemeroff, 2002; van Broekhoven and Verkes, 2003). A recent in vitro study showed that selective serotonin reuptake inhibitors could upregulate the enzyme responsible for the conversion of dihydroprogesterone to THP (Griffin and Mellon, 1999). Hence, the interaction between $\mathrm{P}$ and THP with CRF presented here may represent an important connection between the neurosteroid and neuropeptide systems in the control of emotional behavior.

\section{References}

Abizaid A, Service G, Woodside BC (2004) Effects of estradiol on immediate early gene expression associated with ovulation in lactating rats: role of nutritional status. Brain Res 1001:72-77.

Allan G, Hutchins A, Liu X, Clancy J (2001) Induction of the progesterone receptor gene in estrogen target cells monitored by branched DNA signal amplification. Steroids 66:663-671.

Anagnostaras S, Maren S, DeCola J, Lane N, Gale G, Schlinger B, Fanselow M (1998) Testicular hormones do not regulate sexually dimorphic Pavlovian fear conditioning or perforant-path long-term potentiation in adult male rats. Behav Brain Res 92:1-9.

Arborelius L, Owens MJ, Plotsky PM, Nemeroff CB (1999) The role of corticotropin-releasing factor in depression and anxiety disorders. J Endocrinol 160:1-12.

Aston-Jones G, Rajkowski J, Kubiak P, Valentino RJ, Shipley MT (1996) Role of the locus coeruleus in emotional activation. Prog Brain Res 107:379-402.

Bagis T, Gokcel A, Zeyneloglu HB, Tarim E, Kilicdag EB, Haydardedeoglu B, (2002) The effects of short-term medroxyprogesterone acetate and micronized progesterone on glucose metabolism and lipid profiles in patients with polycystic ovary syndrome: a prospective randomized study. J Clin Endocrinol Metab 87:4536-4540.

Barbaccia ML, Roscetti G, Trabucchi M, Mostallino MC, Concas A, Purdy RH, Biggio G (1996) Time-dependent changes in rat brain neuroactive steroid concentrations and GABAA receptor function after acute stress. Neuroendocrinology 63:166-172.

Barbaccia ML, Roscetti G, Trabucchi M, Purdy RH, Mostallino MC, Concas A, Biggio G (1997) The effects of inhibitors of GABAergic transmission and stress on brain and plasma allopregnanolone concentrations. Br J Pharmacol 120:1582-1588.

Bitran D Hilvers RJ, Kellogg CK (1991) Anxiolytic effects of 3 alphahydroxy-5 alpha[beta]-pregnan-20-one: endogenous metabolites of progesterone that are active at the GABAA receptor. Brain Res 561:157-161.

Bogic L, Gerlach J, McEwen B (1988) The ontogeny of sex differences in estrogen-induced progesterone receptors in rat brain. Endocrinology 122:2735-2741.

Bohmer G, Schmid K, Ramsbott M (1990) Effects of corticotropin-releasing factor on central respiratory activity. Eur J Pharmacol 182:405-411.

Born L, Shea A, Stiener M (2002) The roots of depression in adolescent girls: is menarche the key? Curr Psychiatry Rep 4:449-460.

Brot MD, Akwa Y, Purdy RH, Koob GF, Britton KT (1997) The anxiolyticlike effects of the neurosteroid allopregnanolone: interactions with GABA(A) receptors. Eur J Pharmacol 325:1-7.

Camacho-Arroyo I, Guerra-Araiza C, Cerbon M (1998) Progesterone receptor isoforms are differentially regulated by sex steroids in the rat forebrain. NeuroReport 9:3993-3996.

Carboni E, Wieland S, Lan NC, Gee KW (1996) Anxiolytic properties of endogenously occurring pregnanediols in two rodent models of anxiety. Psychopharmacology (Berl) 126:173-178.

Costa AD, Ma X, Ingram C, Lightman S, Aguilera G (2001) Hypothalamic and amygdaloid corticotropin-releasing hormone $(\mathrm{CRH})$ and $\mathrm{CRH}$ re- 
ceptor mRNA expression in the stress-hyporesponsive late pregnant and early lactating rat. Brain Res Mol Brain Res 91:119-130.

Davis M (1992) The role of the amygdala in conditioned fear. In: The amygdala: neurobiological aspects of emotion, memory and mental dysfunction (Aggleton J, ed), pp 255-305. New York: Wiley.

Deschamps S, Woodside B, Walker CD (2003) Pups presence eliminates the stress hyporesponsiveness of early lactating females to a psychological stress representing a threat to the pups. J Neuroendocrinol 15:486-497.

Dunn AJ, Berridge CW (1990) Physiological and behavioral responses to corticotropin-releasing factor administration: is CRF a mediator of anxiety or stress responses. Brain Res Brain Res Rev 15:71-100.

Fernandes C, Gonzalez M, Wilson C, File S (1999) Factor analysis shows that female rat behavior is characterized primarily by activity, male rats are driven by sex and anxiety. Pharmacol Biochem Behav 64:731-738.

Fernandez-Guasti A, Picazo O (1995) Flumazenil blocks the anxiolytic action of allopregnanolone. Eur J Pharmacol 281:113-115.

Frye C, Wawrzychi J (2003) Effect of prenatal stress and gonadal hormones condition on depressive behaviors of female and male rats. Horm Behav 44:319-326.

Frye C, Petralia S, Rhodes M (2000) Estrous cycle differences in performance on anxiety tasks coincide with increases in hippocampal progesterone and 3alpha,5alpha-THP. Pharmacol Biochem Behav 67:587-596.

Gibbs RB, Gabor R (2003) Estrogen and cognition: applying preclinical findings to clinical perspectives. J Neurosci Res 74:637-643.

Griffin L, Mellon S (1999) Selective serotonin reuptake inhibitors directly alter activity of neurosteroidogenic enzymes. Proc Natl Acad Sci USA 96:13512-13517.

Grosskreutz C, Brody M (1988) Regional hemodynamic responses to central administration of corticotropin-releasing factor (CRF). Brain Res 442:363-367.

Gulinello M, Smith SS (2003) Anxiogenic effects of neurosteroid exposure: sex differences and altered GABAA receptor pharmacology in adult rats. J Pharmacol Exp Ther 305:541-548.

Gupta R, Sen S, Diepenhorst L, Rudnick C, Maren S (2001) Estrogen modulates sexually dimorphic contextual fear conditioning and hippocampal long term potentiation (LTP) in rats. Brain Res 888:356-365.

Gutman D, Nemeroff C (2002) Neurobiology of early life stress: rodent studies. Semin Clin Neuropsychiatry 7:89-95.

Jai Y, Cui YG, Wang XH, Tong JS, Ma DZ, Cai RF, Di FS, Sha JH (2002) Effect of MPA and MPA + TU on the rat spermogenesis and sexual hormones. Zhonqhua Nan Ke Xue 8:109-111.

Jeppsson S (1981) Background, development and properties of progestagens, with special reference to medroxyprogesterone acetate (MPA). Acta Obstet Gynecol Scand Suppl 101:7-10.

Johnson A, File S (1991) Sex differences in animal tests of anxiety. Physiol Behav 49:245-250.

Kontula K, Paavonen T, Luukkainen T, Andersson L (1983) Binding of progestins to the glucocorticoid receptor. Correlation to their glucocorticoid-like effects on in vitro functions of human mononuclear leukocytes. Biochem Pharmacol 32:1511-1518.

Kornblatt JJ, Grattan DR (2001) Lactation alters gamma-aminobutyric acid neuronal activity in the hypothalamus and cerebral cortex in the rat. Neuroendocrinology 73:175-184.

Lee Y, Davis M (1997) Role of the hippocampus, the bed nucleus of the stria terminalis, and the amygdala in the excitatory effect of corticotropinreleasing hormone on the acoustic startle reflex. J Neurosci 17:6434-6446.

Lee Y, Schulkin J, Davis M (1994) Effect of corticosterone on the enhancement of the acoustic startle reflex by corticotropin releasing factor (CRF). Brain Res 666:93-98.

Liang KC, Melia KR, Miserendino MJ, Falls WA, Campeau S, Davis M (1992) Corticotropin-releasing factor: long-lasting facilitation of the acoustic startle reflex. J Neurosci 12:2303-2312.

Lobo R (1999) Progestogen metabolism. J Reprod Med 44:148-152.

Marcondes F, Miguel K, Melo LL, Spadari-Bratfisch R (2001) Estrous cycle influences the response of female rats in the elevated plus-maze test. Physiol Behav 74:435-440.

McAuley JW, Kroboth PD, Stiff DD, Reynolds IJ (1993) Modulation of $(3 \mathrm{H})$ flunitrazepam binding by natural and synthetic progestational agents. Pharmacol Biochem Behav 45:77-83.

Nemeroff CB (2002) New directions in the development of antidepressants: the interface of neurobiology and psychiatry. Hum Psychopharmacol 17 [Suppl 1]:S13-S16.
Neumann I (2003) Brain mechanisms underlying emotional alterations in the peripartum period in rats. Depress Anxiety 17:111-121.

Nilsen J, Brinton R (2003) Divergent impact of progesterone and medroxyprogesterone acetate (Provera) on nuclear mitogen-activated protein kinase signaling. Proc Natl Acad Sci USA 100:10506-10511.

Noda YK, Kamie H, Kamie Y, Nagia T, Nishida M, Nabeshima T (2000) Neurosteroids ameliorate conditioned fear stress: an association with sigma receptors. Neuropsychopharmacology 23:276-284.

Palanza P (2001) Animal models of anxiety and depression: how are females different. Neurosci Biobehav Rev 25:219-233.

Patchev VK, Shoaib M, Holsboer F, Almeida OF (1994) The neurosteroid tetrahydroprogesterone counteracts corticotropin-releasing hormoneinduced anxiety and alters the release and gene expression of corticotropin-releasing hormone in the rat hypothalamus. Neuroscience 62:265-271.

Patchev VK, Hassan AH, Holsboer DF, Almeida OF (1996) The neurosteroid tetrahydroprogesterone attenuates the endocrine response to stress and exerts glucocorticoid-like effects on vasopressin gene transcription in the rat hypothalamus. Neuropsychopharmacology 15:533-540.

Patel F, Funder J, Challis JR (2003) Mechanism of cortisol/progesterone antagonism in the regulation of 15-hydroxyprostaglandin dehydrogenase activity and messenger ribonucleic acid levels in human chorion and placental trophoblast cells at term. J Clin Endocrinol Metab 88:2922-2933.

Pedersen C, Boccia M (2002) Oxytocin links mothering received, mothering bestowed and adult stress responses. Stress 5:259-267.

Pridjian G, Schmit V, Schreiber J (1987) Medroxyprogesterone acetate: receptor binding and correlated effects on steroidogenesis in rat granulosa cells. J Steroid Biochem 26:313-319.

Pryce C, Lehmann J, Feldon J (1999) Effect of sex on fear conditioning is similar for context and discrete CS in Wister, Lewis, and Fischer rat strains. Pharmacol Biochem Behav 64:753-759.

Purdy RH, Morrow AL, Moore Jr PH, Paul SM (1991) Stress-induced elevations of gamma-aminobutyric acid type A receptor-active steroids in the rat brain. Proc Natl Acad Sci USA 154553-154557.

Rabii J, Ganong WF (1976) Responses of plasma "estradiol” and plasma LH to ovariectomy, ovariectomy plus adrenalectomy and estrogen injection at various ages. Neuroendocrinology 20:270-281.

Reddy DS, Kulkarni KS (1997) Differential anxiolytic effects of neurosteroids in the mirrored chamber behavior test in mice. Brain Res 752:61-71.

Rhodes ME, Frye CA (2001) Inhibiting progesterone metabolism in the hippocampus of rats in behavioral estrus decreases anxiolytic behaviors and enhances exploratory and antinociceptive behaviors. Cogn Affect Behav Neurosci 1:287-296.

Saaresranta T, Irjala K, Polo-Kantola P, Polo O (2002) Medroxyprogesteroneinduced endocrine alterations after menopause. Menopause 9:288-292.

Selman P, Wolfswinkel J, Mol J (1996) Binding specificity of medroxyprogesterone acetate and proligestone for the progesterone and glucocorticoid receptor in the dog. Steroids 61:133-137.

Shughrue P, Lane M, Merchenthaler I (1997) Regulation of progesterone receptor messenger ribonucleic acid in the rat medial preoptic nucleus by estrogenic and antiestrogenic compounds: an in situ hybridization study. Endocrinology 138:5476-5484.

Simerly R, Carr A, Zee M, Lorang D (1996) Ovarian steroid regulation of estrogen and progesterone receptor messenger ribonucleic acid in the anteroventral periventricular nucleus of the rat. J Neuroendocrinol 8:45-56.

Sloan D, Kornstein S (2003) Gender differences in depression and response to antidepressant treatment. Psychiatr Clin North Am 26:581-594.

Steenbergen H, Heinsbroek R, Hest AV, Van de Poll NE (1990) Sexdependent effects of inescapable shock administration on shuttlebox escape performance and elevated plus maze behavior. Physiol Behav 48:571-576.

Stephens RJ, Yang H, Rivier J, Tashe Y (1988) Intracisternal injection of CRF antagonist blocks surgical stress-induced inhibition of gastric secretion in the rat. Peptides 9:1067-1070.

Stock H, Caldarone B, Abrahamsen G, Mongeluzi D, Wilson M, Rosellini R (2001) Sex differences on conditioned fear induced enhancement of morphine analgesia. Physiol Behav 72:439-447.

Stoffel-Wagner B, Watzka M, Steckelbroeck S, Ludwig M, Clusmann H, Bidlingmaier F, Casarosa E, Luisi S, Elger CE, Beyenburg S (2003) Allopregnanolone serum levels and expression of 5 alpha-reductase and 3 
alpha-hydroxysteroid dehydrogenase isoforms in hippocampal and temporal cortex of patients with epilepsy. Epilepsy Res 54:11-19.

Swerdlow NR, Britton KT (1994) Alphaxalone, a steroid anesthetic, inhibits the startle-enhancing effects of corticotropin releasing factor, but not strychnine. Psychopharmacology (Berl) 115:141-146.

Swerdlow NR, Geyer MA, Vale WW, Koob GF (1986) Corticotropinreleasing factor potentiates acoustic startle in rats: blockade by chlordiazepoxide. Psychopharmacology (Berl) 88:147-152.

Tashe Y, Goto Y, Gunion M, Vale W, Rivier J, Brown M (1983) Inhibition of gastric acid secretion in rats by intracerebral injection of corticotropinreleasing factor. Science 222:935-937.

Todd BJ, Ladyman SR, Grattan DR (2003) Suppression of pulsatile luteinizing hormone secretion but not luteinizing hormone surge in leptin resistant obese Zucker rats. J Neuroendocrinol 215:61-68.

Torres JM, Ruiz E, Ortega E (2001) Effects of CRH and ACTH administration on plasma and brain neurosteroid levels. Neurochem Res 26:555-558.

Toufexis D, Rochford J, Walker C (1999a) Lactation-induced reduction in rats' acoustic startle is associated with changes in noradrenergic neurotransmission. Behav Neurosci 113:176-184.

Toufexis D, Tesolin S, Huang N, Walker C (1999b) Altered pituitary sensitivity to corticotropin-releasing factor and arginine vasopressin participates in the stress hyporesponsiveness of lactation in the rat. J Neuroendocrinol 11:757-764.

Trawick DR, Bahr JM (1986) , Modulation of the anti-fluorescyl antibody response by estradiol. Endocrinology 118:2324-2330.

Turgeon J, Waring D (2000) Progesterone regulation of the progesterone receptor in rat gonadotropes. Endocrinology 141:3422-3429.

Valentino R, Foote S (1987) Corticotropin-releasing factor disrupts sensory responses of brain noradrenergic neurons. Neuroendocrinology 45:28-36.

Valentino R, Foote S (1988) Corticotropin-releasing factor increases tonic but not sensory-evoked activity of noradrenergic locus coeruleus neurons in unanesthetized rats. J Neurosci 8:1016-1025.

van Broekhoven F, Verkes R (2003) Neurosteroids in depression: a review. Psychopharmacology (Berl) 165:97-110.

Vivian JA, Barros HM, Manitiu A, Miczek KA (1997) Ultrasonic vocalizations in rat pups: modulation at the gamma-aminobutyric acidA receptor complex and the neurosteroid recognition site. J Pharmacol Exp Ther 282:318-325.

Walker DL, Davis M (1997) Double dissociation between the involvement of the bed nucleus of the stria terminalis and the central nucleus of the amygdala in startle increases produced by conditioned versus unconditioned fear. J Neurosci 17:9375-9383.

Walker DL, Davis M (2002) Quantifying fear potentiated startle using absolute versus percent increase scoring methods: implications for the neurocircuitry of fear and anxiety. Psychopharmacology (Berl) 164:318-328.

Walker DL, Toufexis DJ, Davis M (2003) Role of the bed nucleus of the stria terminalis versus the amygdala in fear, stress, and anxiety. Eur J Pharmacol 463:199-216.

Wan Y, Nordeen S (2003) Overlapping but distinct profiles of gene expression elicited by glucocorticoids and progestins. Recent Prog Horm Res 58:199-226.

Wieland S, Lan NC, Mirasedeghi S, Gee KW (1991) Anxiolytic activity of the progesterone metabolite 5 alpha-pregnan-3 alpha-ol-20-one. Brain Res 565:263-268.

Zimmerberg B, Brunelli SA, Hofer MA (1994) Reduction of rat pup ultrasonic vocalizations by the neuroactive steroid allopregnanolone. Pharmacol Biochem Behav 47:735-738. 